\title{
Study on the Unbalanced Development Mechanism of Guangxi Tourism Based on the Strategy of "One Belt, One Route"
}

\author{
Xin Xie, Nianping Zhang \\ Ginlin Tourism University, Guangxi, Guilin, 541006, China
}

\begin{abstract}
The strategy of "One Belt, One Route" provides a rare opportunity for the development of the tourism industry. The characteristics of the tourism industry determine its pilot first position in the "One Belt, One Route" strategy. Guangxi has a unique advantage in terms of geographical position, tourism resources, cultural exchange and preferential policies. However, the contradictions and problems in the development of tourism industry in Guangxi have gradually been highlighted, especially the unbalanced development in the tourism industry. Therefore, this paper will analyze the unbalanced development mechanism of tourism in Guangxi based on the strategy of "One Belt, One Route" and further explore the strategy of Guangxi tourism industry development.

Keywords: Unbalanced Development Mechanism, Guangxi Tourism, Strategy of "One Belt, One Route"
\end{abstract}

\section{Introduction}

The formulation of the major strategic concept of "all the way One Belt, One Route" is not only a new requirement for the development of the new era, but also a new embodiment of China's consistent concept of peaceful development. It can not only promote the cooperation and development of the countries along the route, but also create a favourable environment for the development of the tourism industry. In this era background, Guangxi should seize the opportunity for the further development of tourism to add new impetus, at the same time, but also to play their own advantages, to deal with new challenges. 


\section{The overview of "One Belt, One Route"}

The current global economic growth is weak and all countries are facing serious development problems, and strive to seek new economic growth point. How to strengthen regional cooperation and promote economic development has become a national consensus. China, as a world economic power, has the obligation and responsibility to revitalize the global economy. In order to promote global economic recovery, Xi Jinping President in September and October 2013 has put forward the construction of the "Silk Road Economic Zone" and "the 21st century Maritime Silk Road," the great strategic concept. To build "One Belt, One Route" in line with the fundamental interests of all countries, conform to the trend of economic globalization.

"Area" refers to the "Silk Road Economic Zone", "all the way" refers to the "21st Century Maritime Silk Road." The National Development and Reform Commission, the Ministry of Foreign Affairs and the Ministry of Commerce jointly issued the "Vision and Action for Promoting the Silk Road Economic Belt and the Maritime Silk Road in the 21st Century" on March 28, 2015. As a new round of opening up and going out of our strategic focus, "One Belt, One Route" strategy will help China's economic upgrading to address the existing economic dilemma, but also conducive to Asia and the world economic development. The positioning of Guangxi in this strategy is "band" and "road" an important gateway to organic convergence. This is the Guangxi economy, especially in terms of tourism in Guangxi, is not only a good opportunity for development, but also a big challenge. But in the long run, "One Belt, One Route," the proposed strategy and its development will Guangxi tourism industry more healthy and robust growth has a catalytic role.

\section{Advantages of tourism industry in Guangxi}

\subsection{Location Advantage}

Guangxi is located in the south of China, east of Guangdong, west of Yunnan, northeast by Hunan, south of Beibu Gulf, Hainan and separated by a water, located in the China - ASEAN Free Trade Area Center, has a wide range of geographical advantages, but also Southwest China, South Africa and Southeast Asia to connect the important sea lanes and land access, you can also enter the South Pacific Peninsula from the South Pacific, Indian Ocean, by contrast, convenient entry and exit, location advantage.

\subsection{Resource advantages}

Because of its geographical location, Guangxi has inland provinces do not have the sea scenery resources, water landscape and rich natural landscape, while the cultural landscape with each other. From the strange rocks, green mountains and green water and other beautiful landscape, with man-made pavilions and other 
buildings to improve the tour equipment, harmonious natural landscape and cultural landscape has attracted countless domestic and foreign tourists to sightseeing tour. According to the characteristics of local resources, Guangxi has formed a tourist area of Guangxi with landscape, monuments and ethnic customs as the highlights; GuiNan tourist area with the coastal scenery, border tour and Zhuangxiang as the bright spot; with historical monuments, scenic spots, religious culture, As the highlight of the hometown of Guidong tourist area; to longevity, the Holy Land as the highlight of the revolutionary West Guangxi tourist area, which for the sustainable development of Guangxi tourism provides a good foundation.

\subsection{Policy Advantages}

Because of its geographical location, Guangxi has more advantages in policy. "One Belt, One Route," the in-depth development of the strategy and the China ASEAN Expo permanently settled in Nanning, China - ASEAN Free Trade Area construction and development, gave the Guangxi economy has brought great opportunities for development. Not only that, but also enjoy the Guangxi western development strategy, border development, ethnic minority areas development, poverty alleviation and development, and so preferential policy. These preferential policies will help attract more overseas investment, promote the continuous development of tourism in Guangxi, and continuously improve the economic level.

\section{The problems of the tourism industry development in Guangxi}

\subsection{Environmental constraints.}

Tourism is playing an active role in accelerating economic development, building an open image, promoting urban construction and carrying forward cultural heritage. However, the development of tourism will also bring a certain degree of negative impact on the environment. Want to develop tourism is bound to forest, mineral, land, water and other natural, the original resources to change. For example, some tourist traffic facilities on the original topography to change, resulting in destruction of vegetation along the line. Some hotels and guesthouses and other service facilities will also occupy the occupation of farmland and forest land phenomenon. If we cannot make rational planning of scenic area construction, or use unscientific methods and improper measures, it will cause irreversible adverse consequences to the whole environment, which will make the development of the tourism industry difficult to maintain effectively. 


\section{2 Investment in tourism infrastructure is limited by funding.}

Guangxi traffic network needs to be further improved and its key scenic spots have yet to be further upgraded, which need to continue to strengthen the construction of infrastructure. Investing in tourism infrastructure tends to have a long payback period and low returns relative to other inputs. This makes it less appealing to the capital collection of infrastructure. Some financial institutions will be in the asset returns and financial security considerations in many aspects of the longer-term loans for the total amount of control. Therefore, many large enterprises in Guangxi for the intervention of the tourism industry are not much. Therefore, this has caused the social funds supply shortage and the tourism development fund demand between the long-term existence contradictions. Guangxi has a history of every $100 \mathrm{~km} 2$ of railways and highways in the country after the 20th, and the province's domestic routes relative to other regions is relatively small. Although in recent years, Guangxi is also increasing the construction of infrastructure, but compared to developed areas, the gap is still very large.

\subsection{The per capita consumption in Guangxi is too low}

Per capita consumption level in Guangxi and the national and some developed cities compared to per capita consumption was significantly lower. In Guangxi in 2012 corresponding to the per capita tourist income is $759.92 \mathrm{RMB}$. The average number of inbound tourists is staying in Guangxi every day is about 1.86 days, living in the country's 28th, the average cost is 362 RMB, living in the country 25 th. It can be seen, tourists in Guangxi per capita consumption level are very low and it is difficult to promote the growth of Guangxi tourism revenue. There are many favourable conditions for the development of tourism industry in Guangxi, and the development trend of Guangxi in recent years is good, but there is still a big gap between its own development and the development of world economy and science and technology revolution.

\section{The implementation path of non-balanced development strategy}

The unbalanced development strategy is to allocate effective resources for highefficiency industries and regions, so as to obtain the growth of regional economy, and thus promote the continuous development of other industries or regions. The emergence of this strategic measure is due to the uniformity of natural resources and the allocation of social resources. For the Guangxi region, should be able to grasp their own tourism resources have advantages and geographical advantages, so that limited resources can be as much as possible to the development of tourism resources, management and development, to achieve the continuous increase in tourism income. 


\subsection{Policy guidance}

Policy guidance has a decisive impact on the development of tourism, should pay attention to its appropriate degree of advance, differences, and to focus on other industrial policies with the comprehensive, synergistic and related. Malaysia's tourism competitiveness in Southeast Asia, second only to Singapore, its success is not only rich in tourism resources, a good business climate, but also in government tourism policy-making properly. One approach is to "go out" model, which allows joint venture to take shares of the model, the establishment of cross-border tourism group, so that domestic tourism enterprises to go out; or to encourage overseas tourism enterprises to set up tourism branch, with industry advantages to expand cross- But also to ASEAN countries to establish tourism research information exchange base to explore the open tourism cooperation encountered new situations and new problems, the development of new tourism cooperation projects. In view of the difficulty of financing tourism projects, we will try to establish a tourism industry fund, support a number of tourism enterprises listed on the market, and encourage non-governmental organizations to participate in investment and development of tourism projects.

\subsection{Make efforts to achieve the linkage development of domestic and international tourism industry}

In order to further expand Guangxi and other countries (regions) of tourism cooperation channels, "One Belt, One Route" after the implementation of the strategy, the Guangxi Tourism Development Committee carried out a number of useful open cooperation attempt. However, Guangxi and the Silk Road economic zone countries (regions) of tourism cooperation, the all-round cooperation in the door has not yet opened, the current countries (regions) of the tourist team is only fragmented groups. So how to innovate the form of international tourism propaganda through fruitful promotion activities is of great significance to the actual development of Guangxi tourism. Measures must be taken to develop the tourism industry to enhance the pace of international cooperation in tourism. Currently from the Shanghai FTA successful practice, allow the region registered in line with conditions of Sino-foreign joint travel agencies in addition to the Taiwan region outside the tourism business. The related travel agencies in Guangxi should actively explore the market of BRIC countries in Russia, India, Brazil and South Africa through the adjustment of ownership structure and cooperation with overseas travel agencies, and try to open up the Middle East and EU markets. Overseas market promotion should highlight the national characteristics and highlight the personality characteristics, to provide services. In the key recommendation, should consider the combination of service and demand customization. In overseas promotion must be based on careful prudent principle, the information provided should be more detailed, so that visitors have more choice. 


\subsection{Strengthen the construction of tourism infrastructure}

The timely addition of exotic cultural elements To promote the "all One Belt, One Route" strategy and the integration of tourism, Guangxi to increase hotels, rural hotels, transportation infrastructure to promote the process, should pay more attention to the foundation Facilities facilitation, humanization and internationalization, and strive to international elements, international standards and national symbols, national characteristics of the superposition of integration, to promote the growth of the tourism industry continues to show new heights.

\section{Conclusion}

The strategy of "One Belt, One Route," is undoubtedly an opportunity and a challenge for the tourism industry in Guangxi. Guangxi should fully recognize their own shortcomings, fully exploit their own advantages. In terms of location, it is necessary to strengthen interregional tourism cooperation and balance the regional tourism development. In terms of policy, we should intensify preferential policies and optimize the development environment of tourism economic activities. In the aspect of infrastructure construction, we should perfect the tourism facilities and further promote the balanced development of tourism in Guangxi.

\section{Acknowledgements}

The research work was supported by Guangxi high-level innovation team in Colleges and universities (training unit).

\section{References}

[1] Patty S, Georey W. Consequences of resort development: A comparative study. Tourism Management, 55(12), pp.68-70, 2011

[2] Zhang Y. Tourism and Regional Imbalance in YunNan(China). CAUTHE National Research Conference, 8 (5), pp.87- 91, 2013

[3] Choong K L. A Comparative Study of Caucasian and Asian Visitors to a Cultural Expo in an Asian Setting. Tourism Management, 12(10), pp. 18- 20, 2012

[4] Kozak M. Comparative Assessment of Tourist Satisfaction with Destinations across Nationalities. Tourism Management, 9(6), pp.58- 61, 2011

[5] Bridal J A. Regional Development Policies: An Assessment of Their Evolution and Effects on the Spanish Tourist Model. Tourism Management, 8(4), pp.85-87, 2014 